\title{
ESTÁGIO E PRÁTICAS DE ENSINO NOS CURSOS DE PEDAGOGIA NO ESTADO DE SÃO PAULO
}

\author{
Vanda Moreira Machado Lima
}

Universidade Estadual Paulista - FCT/UNESP, Departamento de Educação, Presidente Prudente, SP. e-mail: vandalima@fct.unesp.br. Financiamento: CNPq.

\section{RESUMO}

O artigo apresenta e discute dados empíricos sobre o estágio nos cursos de Pedagogia do Estado de São Paulo, com o intuito de identificar nas matrizes curriculares a existência de espaços efetivos de orientação e supervisão de estágio e das práticas de ensino. O estudo se insere, na abordagem quantitativa e trata-se de uma pesquisa exploratório-descritiva. Analisa 144 matrizes curriculares dos cursos de Pedagogia oferecidos por instituições públicas e privadas do Estado de São Paulo (2012). Constata-se que metade das instituições investigadas não possui nas matrizes curriculares do curso nenhuma disciplina para orientação e supervisão dos estágios. Há uma diversidade de nomenclaturas de disciplinas relacionadas ao tema, e que não há clareza entre as disciplinas que orientam e supervisionam o estágio na instituição de formação e o próprio estágio curricular obrigatório desenvolvido na escola, futuro espaço de atuação profissional.

Palavras-chave: Estado de São Paulo. Curso de Pedagogia. Formação inicial de professores. Estágio Supervisionado. Prática de Ensino.

\section{STAGE AND PRACTICE OF TEACHING IN PEDAGOGY COURSES IN THE STATE OF SÃO PAULO}

\begin{abstract}
The paper presents and discusses empirical data on the stage in the courses of Pedagogy of the State of São Paulo, in order to identify on curricular spaces the existence of effective guidance and supervision of internship and teaching practices data. The study is a part, the quantitative approach and this is an exploratory-descriptive research. Analyzes 144 curriculum matrices of Pedagogy offered by public and private institutions of the State of São Paulo (2012). It appears that half of the surveyed institutions do not have on curricular course no discipline for guidance and supervision of internships. There are a variety of classifications of disciplines related to the theme, and there is no clarity among the disciplines that guide and supervise the stage at the training institution and compulsory traineeship itself developed in school, future professional workspace.
\end{abstract}

Keywords: State of São Paulo. Pedagogy course.Initial teacher.Supervised.Teaching Practice. TRACT 


\section{INTRODUÇÃO}

Este artigo apresenta e discute alguns resultados da pesquisa coletiva intitulada " $\mathrm{A}$ formação de professores para a Educação Infantil e para os anos iniciais do Ensino Fundamental: análise do currículo dos cursos de Pedagogia de instituições públicas e privadas do Estado de São Paulo", cujo objetivo foi analisar os currículos dos cursos de Pedagogia em sua totalidade, visando identificar como esses estão sendo organizados e qual o tratamento dado aos conhecimentos relacionados à formação do professor para atuar na Educação Infantil e nos anos iniciais do Ensino Fundamental (PIMENTA et al., 2014).

Este estudo fundamentou-se em uma concepção ampla do Estágio compreendendo-o como momento de aproximação com o espaço de atuação do profissional. Baseado no Parecer CNE no 27 (BRASIL, 2001), este estudo entende que

- estágio obrigatório definido por lei deve ser vivenciado durante o curso de formação e com tempo suficiente para abordar as diferentes dimensões da atuação profissional. Deve, de acordo com o projeto pedagógico próprio, se desenvolver a partir do início da segunda metade do curso, reservando-se um período final para a docência compartilhada, sob a supervisão da escola de preferencialmente na condição de assistente de professores experientes. Para tanto, é preciso que exista um projeto de estágio planejado e avaliado conjuntamente pela escola de formação inicial e as escolas de campos de estágio, com objetivos e tarefas claras e que as duas instituições assumam responsabilidades e se auxiliem mutuamente, o que pressupõe relações formais entre instituições de ensino e unidades dos sistemas de ensino. Esses "tempos na escola" devem ser diferentes segundo os objetivos de cada momento da formação. Sendo assim, o estágio não pode ficar sob a responsabilidade de um único professor da escola de formação, mas envolve necessariamente uma atuação coletiva dos formadores (BRASIL, 2001, p.1).

O estágio poderia se iniciar desde o princípio do curso e constituir-se em eixo articulador de todo o currículo, partindo da realidade existente nas escolas, tomando-a como objeto de pesquisa do conjunto das disciplinas, retornando a realidade e propondo formas e caminhos para superação dos desafios evidenciados que impedem uma educação escolar com qualidade para todos.

O estágio e a prática são considerados momentos distintos na formação dos professores na legislação educacional. A 
Resolução CNE/CP 02/2002 (BRASIL, 2002) estipula para a formação de professores para atuar na Educação Básica 400 (quatrocentas) horas de prática como componente curricular, vivenciadas ao longo do curso; e 400 (quatrocentas) horas de estágio curricular supervisionado a partir do início da segunda metade do curso.

Diferente proposta foi apresentada pelas DCN do curso de Licenciatura em Pedagogia (BRASIL, 2006) que estipula carga horária mínima de 3.200h, conforme o 70ำ artigo, divididas em:

I - 2.800 horas dedicadas às atividades formativas como assistência a aulas, realização de seminários, participação na realização de pesquisas, consultas a bibliotecas e centros de documentação, visitas a instituições educacionais e culturais, atividades práticas de diferente natureza, participação em grupos cooperativos de estudos;

II - 300 horas dedicadas ao Estágio Supervisionado prioritariamente em Educação Infantil e nos anos iniciais do Ensino Fundamental, contemplando também outras áreas específicas, se for o caso, conforme o projeto pedagógico da instituição;

III - 100 horas de atividades teórico-práticas de aprofundamento em áreas específicas de interesse dos alunos, por meio, da iniciação científica, da extensão e da monitoria.

Verifica-se que no curso de Pedagogia a legislação não menciona a prática como componente curricular, mas apenas o estágio supervisionado. Nesse sentido, compreendemos o estágio e a prática numa visão de unidade, na qual ambos constituamse numa dimensão investigativa, ou seja, a investigação fundamenta-se como instrumento para assegurar a aproximação à realidade e à possibilidade da reflexão na escola, além de desenvolver nos alunos, futuros professores, a idéia da pesquisa como princípio formativo da docência.

O objetivo desse artigo é apresentar e discutir dados empíricos sobre o estágio nos cursos de Pedagogia do Estado de São Paulo, com o intuito de identificar nas matrizes curriculares dos cursos a existência de espaços efetivos de orientação e supervisão de estágio e das práticas de ensino.

\section{METODOLOGIA}

O estudo se insere, na abordagem quantitativa e trata-se de uma pesquisa exploratório-descritiva na qual se busca, preponderantemente, a descrição e análise dos dados de forma articulada e aprofundada (LUDKE; ANDRÉ, 1986).

Inicialmente identificou-se 283 cursos de Pedagogia em atividade no Estado de São Paulo cadastrados no site do Inep/MEC 
(agosto, 2012), mas foram excluídos 30 cursos que não estavam sendo ofertados, chegando-se assim a 253 cursos. Ao consultar às páginas eletrônicas das instituições tivemos acesso a 144 matrizes curriculares que se constituíram em objeto de estudo desta pesquisa. Elaboramos um instrumento de coleta de dados constituído de duas partes, uma com os dados gerais da instituição e do curso e a outra com várias categorias de análise das matrizes curriculares. A pesquisa não foi apresentada ao Comitê de ética em Pesquisa (CEP) por não envolver seres humanos. Para a análise da categoria 5 "Conhecimentos relativos ao estágio supervisionado e as práticas de ensino", apresentada neste texto, selecionamos todas as disciplinas que explicitassem em sua nomenclatura relação com o espaço de atuação do pedagogo, como por exemplo, Estágio Supervisionado, Práticas de Ensino e Práticas Pedagógicas, dentre outras. Trabalhamos com os dados empíricos primeiramente contemplando as disciplinas ligadas ao Estágio que não apresentaram a especificação do nível de ensino e, posteriormente, as disciplinas relacionadas ao Estágio com especificações, como Educação Infantil, Ensino Fundamental e Gestão Educacional.

\section{RESULTADOS}

Identificou-se que dos 144 cursos identificados $86,80 \%$ (125) são ofertados em instituições privadas e apenas 13,20\% (19) em públicas, sendo 8 cursos ofertados em instituições estaduais, 2 em federais e 9 em municipais. Verificou-se que 99 cursos estão instalados em Faculdades, 19 em Centros Universitários e 26 em Universidades. Quanto ao tempo de integralização dos cursos, 67 são oferecidos em 4 anos, 75 em menos de 4 anos dos quais 47 (32,63\%) são oferecidos em 3 anos e, 2 cursos oferecidos em mais de 4 anos. Ao analisar o cruzamento entre o tempo de integralização e a categoria administrativa da instituição "os dados indicam que os cursos de menor duração (6 semestres) são predominantemente oferecidos pelas instituições privadas, ou seja $43(91,49 \%)$ dos 47 privados" (PIMENTA et al., 2014, p. 13).

De modo geral os dados evidenciam que "a formação do Pedagogo no país ocorre, predominantemente, em instituições privadas, em sua maioria Faculdades e Centros Universitários, com duração menor do que 4 anos (ou 8 semestres)". (PIMENTA et al., 2014, p. 14).

$$
\text { Constatou-se que } 50,35 \% \text { (72) das }
$$
instituições pesquisadas oferecem disciplinas referentes ao Estágio Supervisionado, as demais 49,65\%(71) não oferecem nenhuma disciplina. Dentre os 72 cursos identificados 
que oferecem disciplinas de Estágio, 44,97\% não identificam o nível de ensino na nomenclatura das disciplinas. Daquelas que identificam o nível de ensino percebeu-se um equilíbrio entre Educação Infantil (18,60\%), Ensino Fundamental (19,38\%) e Gestão Educacional (17,05\%). Assim a docência prevalece nos cursos de Pedagogia no Estado de São Paulo.

A maioria das instituições, aproximadamente $64 \%$, oferece entre 2 e 5 disciplinas relacionadas ao Estágio Supervisionado em seus cursos de Pedagogia, mas encontramos instituições oferecendo 14 disciplinas.

Das 72 instituições que oferecem disciplinas relacionadas ao Estágio, temos um total de 348 disciplinas, sendo $71,8 \%$ (250) sem especificação do nível de ensino e $28,2 \%$ (98) com especificação, a saber: 31 na Educação Infantil, 34 no Ensino Fundamental, 30 na Gestão Educacional e 3 concomitante na Educação Infantil e Ensino Fundamental ${ }^{1}$.

Há uma diversidade de nomenclatura das disciplinas relacionadas com o Estágio Supervisionado sem especificação de nível de ensino, contemplando três blocos: estágio supervisionado $(23,2 \%)$, práticas e pesquisa $(72 \%$,$) e estágio, práticas e pesquisa (4,8 \%)$. No primeiro bloco "estágio supervisionado",

\footnotetext{
${ }^{1}$ As três disciplinas que contemplam na nomenclatura os níveis Educação Infantil e o Ensino Fundamental são: Ação pedagógica na educação infantil e anos iniciais, Prática de ensino em educação infantil e séries iniciais do ensino fundamental e Conhecimentos relativos ao estágio no Ensino Fundamental e na Educação Infantil.
}

há disciplinas como "Projetos Pedagógicos e Supervisão de Estágio: Ações Educacionais", “Projetos Pedagógicos e Supervisão de Estágio: docência no ensino superior". No bloco de "práticas e pesquisa" temos como exemplos:; "Práticas de Ensino: Trabalho Coletivo em Espaços Coletivos"; "Práticas de Ensino: Ensino na Educação Básica: o que, como e por que"; "Prática de Ensino e Formação Docente"; "Prática de Ensino: a Didática na Práxis Pedagógica"; "Prática de Ensino: Princípios do Ciclo Docente"; "Prática de Ensino: Estágio e Vivência Científica"; "Prática de Ensino: Procedimentos Metodológicos". E no bloco "estágio, práticas e pesquisa" a nomenclatura envolve: “Orientação à prática docente de estágio supervisionado", "Estágio e Prática", Atividades práticas supervisionadas" e outras.

Das 31 disciplinas relacionadas ao estágio da Educação infantil a maioria 45,2\% corresponde ao enfoque Práticas e pesquisa. Das 34 disciplinas relacionadas ao estágio no Ensino Fundamental nota-se um equilíbrio entre o Estágio propriamente dito e na Prática e pesquisa.

As disciplinas relacionadas ao Estágio Supervisionado na Gestão Educacional foram subdivididas em Espaço Escolar (86,6\%), Espaço não escolar (10\%) e Espaço escolar e não escolar (3,4\%). As disciplinas de Estágio em espaço escolar podem ser agrupadas de 
acordo com os enfoques: Espaço escolar: Estágio Supervisionado (53,3\%), Espaço escolar: Práticas e Estágio Supervisionado (13,3\%) e Espaço Escolar: práticas e pesquisa (20\%), Espaço não escolar (10\%) e Espaço Escolar e não Escolar (3,3\%).

Em relação à carga horária das disciplinas constata-se uma diversidade imensa, variando entre $40 \mathrm{~h}$ e $814 \mathrm{~h}$ dedicadas ao estágio e práticas de ensino. Das 72 instituições $84,7 \%$ (61) possuem uma carga horária total de disciplinas relacionadas ao Estágio supervisionado entre $100 \mathrm{~h}$ e $399 \mathrm{~h}$, porém temos 14 instituições com carga horária entre $400 \mathrm{~h}$ a $699 \mathrm{~h}$ e 2 instituições entre $800 \mathrm{~h}$ e $814 \mathrm{~h}$.

\section{DISCUSSÃO}

Nessa pesquisa selecionamos para a reflexão sobre o Estágio Supervisionado as disciplinas que explicitamente se relacionavam à supervisão e orientação de estágio ou das práticas de ensino, não considerando, portanto, o estágio obrigatório realizado pelos alunos. No entanto, observase que em alguns cursos a disciplina de Estágio corresponde a orientação, supervisão e a permanência do aluno na escola campo.

Aproximadamente, metade das instituições investigadas não possui nas matrizes curriculares dos cursos de Pedagogia nenhuma disciplina para orientação e supervisão dos estágios. Dentre os 72 cursos que oferecem disciplinas relacionadas ao Estágio e Práticas de ensino, $44,7 \%$ não identifica na nomenclatura o nível de ensino. E dentre os 71 cursos que identificam o nível de ensino a docência prevalece $(37,98 \%)$ sobre a área de gestão educacional $(17,05 \%)$.

Vale ressaltar que o 8o artigo, inciso IV a DCN (BRASIL, 2006) estabelece que no projeto pedagógico da instituição, a integralização de estudos se efetivará por várias atividades, dentre elas temos o estágio curricular que deverá ser realizado ao longo do curso, assegurando aos graduandos experiência de exercício profissional, em ambientes escolares e não-escolares.

O curso de Pedagogia historicamente tem priorizado em seus projetos pedagógicos a formação do professor para atuar na educação infantil e nos anos iniciais do ensino fundamental, mesmo que a DCN (BRASIL, 2006) possibilite uma formação mais abrangente, envolvendo o espaço escolar e não escolar.

Percebeu-se a diversidade de nomenclatura das disciplinas relacionadas ao estágio presentes nas matrizes pesquisadas, - que aponta para a relevância de se prosseguir com a investigação visando analisar como se efetivam essas disciplinas na formação do pedagogo. Algumas questões surgem: Como desenvolver um estágio supervisionado com qualidade sem assegurar 
espaços efetivos de orientação e supervisão nas matrizes curriculares dos cursos de pedagogia? Como esses estágios supervisionados estão se desenvolvendo em nossos cursos de Pedagogia no Estado de São Paulo?

Defendemos que o Estágio é um momento essencial na formação do professor, para que tenha significado é necessário envolver atividades orientadas e supervisionadas, como por exemplo:

[...] ir às escolas e realizar observações, entrevistas, coletar dados sobre determinados temas abordados nos cursos, problematizar, propor e desenvolver projetos nas escolas; conferir os dizeres de autores e da mídia, as representações e os saberes que têm sobre a escola, 0 ensino, os alunos, os professores, nas escolas reais; começar a olhar, ver e analisar as escolas existentes com olhos não mais de alunos, mas de futuros professores. (PIMENTA, 1999, p.28).

\section{CONCLUSÕES}

As matrizes curriculares dos cursos de Pedagogia analisados refletem alguns desafios identificados em outras pesquisas, como a indefinição do campo pedagógico, a dispersão do objeto da pedagogia e a redução da pedagogia à docência. Conseqüentemente, os cursos de Pedagogia, em sua maioria, não estão dando conta de formar o pedagogo e tampouco o professor para a educação infantil e os anos iniciais da educação básica (PIMENTA et al., 2014).

Constata-se a ausência de espaços para a orientação e supervisão dos estágios e a complexidade da investigação sobre esse campo de pesquisa, visto que há uma diversidade de nomenclaturas de disciplinas relacionadas ao tema, mas não há clareza entre as disciplinas que orientam e supervisionam o estágio na instituição de formação e o próprio estágio curricular obrigatório desenvolvido na escola, futuro espaço de atuação profissional.

Recentemente o Conselho Estadual de Educação de São Paulo fixou as Diretrizes Curriculares Complementares para a formação de docentes para a Educação Básica nos Cursos de Graduação de Pedagogia, Normal Superior e Licenciaturas, oferecidos pelos estabelecimentos de ensino superior vinculados ao sistema estadual, pela Deliberação

n. $111 / 2012$ e 126/2014.Observa-se uma inovação na compreensão do Estágio, visto que estabelece aos cursos de Pedagogia a carga horária mínima para o estágio de 400 horas sendo dividida em:

I - 200 (duzentas) horas de estágio na escola, compreendendo o acompanhamento do efetivo exercício da docência na educação 
infantil e nos anos iniciais do ensino fundamental e vivenciando experiências de ensino, na presença e sob supervisão do professor responsável pela classe na qual o estágio está sendo cumprido e sob orientação do professor da Instituição de Ensino Superior;

II - 200 (duzentas) horas dedicadas às atividades de gestão do ensino, na educação infantil e nos anos iniciais do ensino fundamental, nelas incluídas, entre outras, as relativas ao trabalho pedagógico coletivo, conselhos da escola, reuniões de pais e mestres, reforço e recuperação escolar, sob orientação do professor da Instituição de Ensino Superior e supervisão do profissional da educação responsável pelo estágio na escola, e, atividades teórico práticas e de aprofundamento em áreas específicas, de acordo com o projeto políticopedagógico do curso de formação docente. (SÃO PAULO, 2014, art. 7ㅇ).

Essa legislação estadual poderá contribuir significativamente para um repensar e reelaborar das propostas de estágio supervisionado desenvolvidas nos cursos de Pedagogia, visto que aborda duas dimensões da docência, o ensino em sala de aula propriamente dito e a gestão do ensino, como descreve o trecho acima. Outro aspecto fundamental, refere-se a ênfase que a legislação estadual traz para a orientação e supervisão do estagiário, e a necessária parceria entre instituição de ensino superior e a escola de educação básica. Entretanto, vamos acompanhar como de fato essa legislação se efetivará nos cursos de Pedagogia no Estado de São Paulo.

\section{REFERÊNCIAS}

BRASIL. Ministério da Educação. Conselho Estadual da Educação. Resolução CNE/CP no 1/2006. Institui Diretrizes Curriculares Nacionais para o Curso de Graduação em Pedagogia, licenciatura. Brasília: MEC/CNE, $2006 . \quad$ Disponível em: <http://portal.mec.gov.br>. Acesso em: 10 mar. 2010.

Ministério da Educação. Conselho Nacional de Educação. Conselho Pleno. Resolução CNE/CP no 2/2002. Institui a duração e a carga horária dos cursos de licenciatura, de graduação plena, de formação de professores da Educação Básica em nível superior. Disponível em: $<$ http://portal.mec.gov.br/cne/arquivos/pdf/ >. Acesso em: 10 dez. 2013.

Ministério da Educação. Conselho Nacional de Educação. Conselho Pleno. Parecer CNE/CP no 27/2001, de 27 de outubro de 2001. Disponível em: <http://portal.mec.gov.br/cne/arquivos/pdf/ >. Acesso em: 10 dez. 2013.

LÜDKE, M.; ANDRÉ, M. E. D. A. Pesquisa em educação: abordagens qualitativas. São Paulo: EPU, 1986.

PIMENTA, S. G. et al. A formação de professores para a Educação Infantil e para os anos iniciais do Ensino Fundamental: análise do currículo dos cursos de Pedagogia de instituições públicas e privadas do Estado 
de São Paulo. Relatório Técnico de Pesquisa, fev. 2014. 47 p.

PIMENTA, S. G. (Org.) Saberes Pedagógicos e atividade docente. São Paulo: Cortez, 1999.

SÃO PAULO. Conselho Estadual de Educação de São Paulo. Deliberação CEE 126/2014 que Altera dispositivos da Deliberação 111/2012. Diário Oficial Poder Executivo, São Paulo, 14 jun. 2014. Seção I, v. 124, n. 110, p. 21.

. Conselho Estadual de Educação de São Paulo. Deliberação CEE 111/2012 que fixa Diretrizes Curriculares Complementares para a Formação de Docentes para a Educação Básica nos Cursos de Graduação de Pedagogia, Normal Superior e Licenciaturas, oferecidos pelos estabelecimentos de ensino superior vinculados ao sistema estadual. Diário Oficial Poder Executivo, São Paulo, 03 fev. 2012. Seção I, p.46.

Recebido para publicação em 30/07/2014

Revisado em 25/08/2014

Aceito em 02/09/2014 